\title{
Clinical applications of molecular biology to diagnostic microbiology
}

\author{
R C Matthews, J P Burnie
}

\section{Introduction}

Molecular biology has had a major impact on research in microbiology but its application to routine clinical problems has been slow to filter through to diagnostic bacteriology laboratories. This is not necessarily because bacteriologists are unwilling to embrace these new techniques. The fact is that many bacterial pathogens are easy to culture within one to two days, with the added advantage that this confirms viability and can be followed by antibiotic sensitivity testing. The situation is rather different in a virology laboratory, where culture takes longer or is impossible, and sensitivity testing is not such an issue. It is not surprising, therefore, that molecular biology, particularly the polymerase chain reaction (PCR), has found more routine applications in the virology laboratory.

Nevertheless, molecular biology has a great deal to offer, either directly or indirectly, in certain areas of diagnostic bacteriology. These include the development of serological tests, nucleic acid hybridisation assays, and genetically based typing systems.

\section{Development of serological tests and other assays}

Serological tests are useful when it is difficult or impossible to grow a micro-organism, when growth is slow, or when there is a need to assess the meaning of a positive culture. The PCR has the advantage that it detects the microbial DNA itself, rather than the antibody response to the organism. It is also very sensitive. This is an asset when examining small quantities of biopsy material taken by an invasive technique, or when the pathogen is greatly diluted, as when examining environmental water samples. It has been successfully applied to the rapid diagnosis of tuberculous meningitis. ${ }^{1}$ It was more sensitive than culture or an enzyme linked immunosorbent assay (ELISA) for cerebrospinal fluid (CSF) antibodies in cases of highly probable tuberculous meningitis based on clinical features. The PCR detected 15 out of 20 cases $(75 \%)$, compared with $11(55 \%)$ by ELISA and four $(20 \%)$ by culture. There were some false positive results due to cross-contamination, a common problem with the PCR, but these were identified by repeat sampling of the stored CSF. Patients with tuberculous meningitis on repeat testing of the same CSF samples remained positive. Recommendations for avoiding contamination have been drawn up by Kwok and Higuchi. ${ }^{2}$ The PCR has also increased the sensitivity of detection of HIV-1, hepatitis B, and cytomegalovirus. ${ }^{3}$ Judicious use of selective gene probes and PCR applied to the examination of environmental water samples has been used to distinguish between total and faecal coliform bacteria (Atlas $\mathrm{R}$, et al. American Society of Microbiologists annual meeting, 1984) and total Legionella versus Legionella pneumophila (Mahbubari $\mathrm{M}$, et al ASM Conference in Biotechnology, Florida, 1989).

The PCR has several inherent disadvantages. It does not distinguish viable from nonviable organisms and is not yet quantifiable. And this may make it difficult to assess the relevance of a positive PCR if the organism under examination can exist as an asymptomatic commensal or a pathogen and the specimen is not from a sterile site. Many antigen based serological tests can be used to monitor the patient's response to treatmentthe titre falling if this is successful. Such subtleties are likely to be lost with the PCR reaction, which is either positive or negative and may continue to be positive when the organism is no longer viable.

DNA recombinant technology also provides a means of producing large amounts of specific microbial antigens without the need for biochemical purification. This approach has been applied to the development of a serological test for endocarditis. ${ }^{4}$ Immunoblotting serum samples from patients with endocarditis due to Enterococcus faecalis showed a strong $\operatorname{IgM}$ and IgG response to an antigen of 112 kilodaltons. ${ }^{5}$ The former faded with successful antibiotic treatment. The antigen was cloned into the expression vector, $\lambda$ gt 11 , the library being screened with sera from patients with enterococcal endocarditis. Preparative amounts of the resulting $\beta$-galactosidase- 112 kilodalton fusion protein were obtained by subcloning the positive clone into the lysogenic Escherichia coli strain Y1089. The fusion protein was purified from the lysogenised $E$ coli by affinity chromatography, with a column of covalently bound $\beta$-galactosidase monoclonal antibody. It was then used to produce an indirect ELISA for enterococcal endocarditis, measuring the patient's antibody response to the 112 kilodalton antigen. ${ }^{46}$ The assay for measuring IgG readily distinguished enterococcal endocarditis (optical density of $>0.8$ ) from endocarditis caused by staphylococci (optical density of $<0.243$ ) or streptococci (optical density of $<0.656$ ). ${ }^{4}$ The only clinically relevant cross-reaction occurred with Streptococcus bovis, and on immunoblotting antiserum raised against the fusion protein 
was shown to cross-react with the 48 kilodalton antigen of $S$ bovis. Falling serum $\operatorname{IgM}$ to the fusion protein correlated with clinical recovery in response to antibiotic treatment.

In some cases it is difficult to produce a stable lysogen in $E$ coli Y1089. An alternative approach is to sequence the cloned antigen, map the epitopes along the derived amino acid sequence, and then synthesise specific peptide epitopes for use in a serological test. This was applied to the development of a serological test for systemic candidosis. ${ }^{67}$ Having cloned and sequenced the immunodominant 47 kilodalton antigen of Candida albicans, epitopes were mapped by Geysen's Pepscan technique. A complete set of overlapping peptides, 9 amino acids long, were synthesised on polyethylene rods and probed with infected patients' sera, in ELISA format. Dominant epitopes were synthesised, conjugated to keyhole limpet haemocyanin, and used to raise rabbit polyvalent antisera and murine monoclonal antibodies. These antibody probes were then used to detect circulating candidal 47 kilodalton antigen (heat shock protein 90 ) in the sera of systemically infected patients.

\section{Nucleic acid hybridisation assays}

DNA probes have so far had a limited part to play in diagnostic bacteriology. They have been particularly useful in distinguishing virulent from avirulent strains of bacteria, such as enterotoxin producing strains of $E$ coli $^{8}$ or toxigenic strains of Staphylococcus aureus. ${ }^{9}$ These techniques have been limited to the reference or research laboratory. The main reason for this is the reliance on radioisotopes for labelling the DNA probe, which have a short functional half-life, are expensive, and pose the problems of radiation exposure and isotope disposal. An increasing number of nonisotopic enzymatic and chemical labelling methods have now been described, but the sensitivity of these is often lower than that of ${ }^{32} \mathrm{P}$.

Digoxigenin (Boehringer Mannheim) may be an important advance in this respect. It compared favourably with ${ }^{32} \mathrm{P}$ when used to label probes for hybridisation to Southern blots of Pasteurella haemolytica DNA digests. ${ }^{10} \mathrm{~A}$ comparison has been performed with DNA probes for the Vero cytotoxin genes (VT1 and VT2) of Vero cytotoxin producing $E$ coli, labelled with ${ }^{35} \mathrm{~S}$, biotin of digoxigenin. ${ }^{11} \mathrm{The}$ ${ }^{35} \mathrm{~S}$-labelled probes gave the most reliable, clearly distinguishable results. The digoxigenin labelled probe performed well with bacterial isolates but gave some false positive results when applied directly to faecal samples. It had the financial advantage of being reusable several times. The biotin system was the least reliable, giving some very strong false positive results with non- $E$ coli enterobacteria.

Other disadvantages of hybridisation assays include the lengthy procedures involved in sample preparation, the need to perform assays at relatively high temperatures, and, often, the low sensitivity, compared with other diagnostic methods, for detecting microbial pathogens in clinical specimens. The procedures involved have recently been comprehensively reviewed. ${ }^{12}$

A nucleic acid hybrisation assay is frequently used to confirm the specificity of a PCR, often with a third DNA probe which is internal to the two primers selected for the PCR. This combines the ease and sensitivity of PCR with the specificity of DNA hybridisation. An intrinsic advantage of DNA hybridisation is that most microbes have both highly conserved DNA sequences, present in all the different strains of a species, and strain specific sequences. Therefore, by judicious selection of DNA probes it is possible to tailor the assay for the detection of one particular strain or all the strains in a species. ${ }^{12}$ The presence of conserved, non-coding DNA can itself be an asset. No single immunoassay can detect all the serotypes of the antigenically diverse enteroviruses, but DNA probes from highly conserved, non-coding regions of the genome were capable of binding to nucleic acids from multiple types of enteroviruses. ${ }^{13}$

\section{Typing systems}

This area has been one of the most productive applications of molecular biology to medical microbiology. Taking as an example $C$ albicans, this species of yeast can be typed by four distinct genetically based techniques. The first of these to be described was DNA fingerprinting by conventional ethidium bromide-agarose gel electrophoresis, polymorphic fragments of DNA being generated by frequent cutting enzymes such as EcoRI, Hind III, or Bam HI. ${ }^{14}$ Typing is based on the presence, absence, and relative positions of several intense bands which are generated by the cutting of repetitive DNA fragments at specific sequences-for example, ribosomal DNA. The technique has been successfully applied to clinical situations, in the identification of outbreaks of systemic candidosis due to cross-infection by a single strain, ${ }^{15}$ and in the comparison of isolates from patients with AIDS taken from different sites and at different times. ${ }^{16}$ All isolates were typable by DNA fringerprinting and the level of reproducibility was high, but a single DNA fingerprint type accounted for about $60 \%$ of isolates. ${ }^{15}$

Mitochondrial DNA is believed to evolve more rapidly than nuclear DNA in a variety of taxa. Olivo et al examined the mitochondrial DNA of $C$ albicans, following digestion with Hay III, by probing Southern blots with cloned mitochondrial DNA fragments. ${ }^{17}$ They demonstrated four distinct polymorphisms among the 26 isolates examined. A disadvantage of this technique is that it limits the procedure to laboratories with the necessary DNA probes and radioisotope facilities.

Pulsed-field gel electrophoresis (PFGE) has also been applied to the examination of different stains of $C$ albicans, but is probably unsuitable as a typing system. PFGE differs from conventional agarose gel electrophoresis in that it separates much larger chromosomal DNA fragments by virtue of switching the 
current between two sets of electrodes set at an obtuse angle. Such systems are now commercially available and have been refined so as to give straight tracks with high resolution of bands once the pulse time, voltage, and run time has been optimised (for example, the CHEF-DR II, Bio-rad). $C$ albicans, a diploid eukaryote, separates to give multiple chromosomal bands on PFGE, but is unusual in that the migration distances of some of these chromosomes vary considerably from one isolate to the other. ${ }^{18}$ However, it is probably less suitable as a typing system than conventional DNA fingerprinting because changes can occur within a single stain on repeated subculture.

More recently, the PCR has been applied to the typing of $C$ albicans, using short empiric oligonucleotides as a single primer to generate multiple bands (unpublished observations). A major advantage of this approach is its speed and simplicity: the DNA extracted does not have to be as pure or as much as that required for restriction enzyme digests.

Which of these typing systems is optimal varies greatly with the organism under investigation. For example, we found that we could not type Bordetella pertussis isolates by conventional DNA fingerprinting with a selection of the common restriction enzymes. All produced an identical fingerprint. The same isolates examined by PFGE, after digestion with the rare cutting enzyme $X b a I$, generated 17 different DNA types. ${ }^{19}$ In the case of methicillin resistant $S$ aureus we found that immunoblot fingerprinting provided a suitable typing system that was superior to conventional DNA fingerprinting. ${ }^{20}$

\section{Concluding remarks}

Molecular biology has a great deal to offer clinical microbiology services, even though many of the currently used techniques are largely limited to reference or research laboratories. Wherever possible techniques such as PCR and DNA fingerprinting by conventional agarose gel electrophoresis are to be encouraged because these can be most readily adopted by laboratories with the minimum of specialised equipment.

RCM is a Wellcome Senior Research Fellow.

1 Shankar P, Manjunath N, Mohan KK, Prasad K, Behari Shriniwas M, Ahuja GK. Rapid diagnosis of tuberculous meningitis by polymerase chain reaction. Lancet 1991;337:5-7.

2 Kwok S, Higuchi R. Avoiding false positives with PCR. Nature 1989;339:237.

3 Matthews RC. PCR in the diagnosis of infectious diseases. In: Matthews RC, Burnie JP, eds. Handbook of serodiagnosis in infectious diseases. Oxford: Butterworth-Heinemosis in infectious $1991: 143-8$.

4 Burnie JP, Clark I. Diagnosing endocarditis with the cloned $112 \mathrm{kDa}$ antigen of Enterococcus faecalis. J Immunol Methods 1989;123:217-25.

5 Burnie JP, Holland M, Matthews RC, Lee W. Role of immunoblotting in the diagnosis of culture negative and enterococcal endocarditis. J Clin Pathol 1987;40:1149-58.

6 Matthews RC. Cloning microbial antigens into lambda gt 11 for the development of serological tests. In: Matthews RC, Burnie JP, eds. Handbook of serodiagnosis in infectious diseases. Oxford: Butterworth-Heinemann, 1991:85-94.

7 Matthews RC. Burnie JP, Lee W. The application of epitope mapping to the development of a new serological test for mapping to the development of a new serological test for
systemic candidosis. J Immunol Methods 1991;143:73-9.

8 Sack RB. Enterotoxigenic Escherichia coli: identification and characterization. $J$ Infect Dis 1985;142:279-86.

9 Bergdoll MS, Crass B, Reisser RF, et al. A new staphylococcal enterotoxin $F$, associated with toxic-shock syndrome Staphylococcus aureus isolates. Lancet 1981;i:1017-21.

10 Cox N, Johnston J, Szarka Z, Wright DJM, Archard LC. Characterization of an rRNA gene-specific cDNA probe; applications in bacterial identification. $J$ Gen Microbiol 1990;136:1639-43.

11 Thomas A, Smith HR, Willshaw GA, Rowe B. Nonradioactively labelled polynucleotide and oligonucleotide DNA probes, for selectively detecting Escherichia coli strains producing Vero cytotoxins VT1, VT2 and VT2 variant. Mol Cell Probes 1991;5:129-35.

12 Viscidi RP. Nucleic acid hybridization assays-DNA probes. In: Matthews RC, Burnie JP, eds. Handbook of serodiagnosis in infectious diseases. Oxford: ButterworthHeinemann, 1991:106-42.

13 Rotbart HA, Levin MJ, Villarreal LP. Use of subgenomic poliovirus DNA hybridization probes to detect the major subgroups of enteroviruses. J Clin Microbiol 1984;20:1105-8.

14 Scherer S, Stevens DA. Application of DNA typing methods to epidemiology and taxonomy of Candida species. $J$ ods to epidemiology and taxonom

15 Matthews RC, Burnie JP. The rapid identification of outbreaks of systemic candidosis by DNA fingerprinting. Br Med J 1989;298:354-7.

16 Whelan WL, Kirsch DR, Kwon-Chung KJ, Wahl SM, Smith PD. Candida albicans in patients with the acquired immunodeficiency syndrome: absence of a novel hypervirulent strain. J Infect Dis 1990;162:513-8.

17 Olivo PD, McManus EJ, Riggsby WS, Jones JM. Mitochondrial DNA polymorphism in Candida albicans. $J$ Infect Dis 1987;156:214-5.

18 Magee PT, Rikkerink EHA, Magee BB. Methods for the genetics and molecular biology of Candida albicans. genetics and molecular biology
Analyt Biochem 1988;175:361-72.

19 Khattack MV, Matthews RC, Burnie JP. Is Bordetella pertussis clonal? Br Med J 1992;304:813-5

20 Burnie JP, Matthews RC, Lee W, Murdoch D. A comparison of immunoblot and restriction patterns in characterising methicillin resistant isolates of Staphylococcus aureus. J Med Microbiol 1989;29:225-61. 